https://doi.org/10.24201/aap.2021.318

ARTÍCULO

\title{
Los incendios de 2019-2020 en Australia
}

\section{The 2019-2020 Australian Bushfires}

\author{
CARLOS MONDRAGÓN \\ https://orcid.org/0000-0002-2060-2928 \\ El Colegio de México, A.C., México
}

Recepción: 6 de octubre de 2020

Aceptación: 7 de abril de 2021

Resumen: Este texto ofrece un bosquejo de los antecedentes políticos, históricos y ambientales en los que se dio la estación de incendios forestales 2019-2020 en Australia. En la parte política, el énfasis está en la tendencia que ha seguido la agenda ambiental de los distintos gabinetes federales durante los últimos 30 años, especialmente en relación con el control de emisiones de gases de efecto invernadero. En cuanto al medio ambiente, se trazan los contornos de los principales fenómenos climáticos que afectan la geografía australiana en el presente, así como la historia de las relaciones humano-ambientales que han esculpido esa geografía desde tiempos ancestrales. Posteriormente se hace un recuento de los incendios, sus consecuencias y sus costos.

Palabras clave: Australia; incendios forestales; política climática; historia ambiental.

\footnotetext{
Abstract: This text provides an outline of the political, historical and environmental background to the 2019-2020 fire season in Australia. On the political side, the emphasis is on the overall trends that mark the environmental agenda of different prime ministers over a 25 -year period, starting in 1996, especially in relation to control of greenhouse gas emissions. 
Regarding the environment, the contours of the main climatic phenomena that affect the Australian geography are laid out, including a very brief summation of the humanenvironmental relationships that have sculpted that geography since ancient times. Subsequently, a brief recounting is made of the fires, their consequences, and their costs.

Keywords: Australia; bushfires; climate policies; environmental history.

"El bush australiano es tan real como imaginario.

Es real en el sentido en que crece [y] aloja vida silvestre. Es imaginario en tanto aloja la vida misma de la mente australiana. Es $[\ldots]$ la fuente de la idea de la nación." Don Watson (2014: 66)

Entre junio de 2019 y abril de 2020, 19 millones de hectáreas (186 000 kilómetros cuadrados) de territorio australiano sufrieron fuegos destructivos. Del total de hectáreas afectadas, 12.6 millones correspondieron a bosques primarios y ecologías con cubierta arbórea, un tipo de geografía denominada genéricamente bushland. ${ }^{1}$ De acuerdo con un estudio preliminar comisionado por la World Wildlife Fund de Australia e implementado por un consorcio de universidades prominentes, hasta 3000 millones de animales habrían perecido como consecuencia directa de estos incendios. Por comparación, la cifra de decesos humanos (34 personas) y de destrucción de propiedad inmobiliaria (más de 3000 casas residenciales) palidece, sin haber sido menos trágica (World Wildlife Fund 2020).

El propósito de este artículo es ofrecer un bosquejo de los antecedentes climáticos, socioambientales y políticos que sentaron el contexto para una de las estaciones de incendios

\footnotetext{
${ }^{1}$ El término bush guarda un singular valor semántico en el contexto australiano. En sentido literal se traduce como "matorral", un espacio abigarrado de matas espesas. Históricamente bush comunicaba la imagen de un territorio sin cultivar y se aplicaba a las vastas extensiones áridas y semiáridas que caracterizan el hinterland australiano. El término fue introducido por los primeros colonos británicos, quienes lo usaron para describir un continente que durante casi dos siglos fue declarado Terra Nullius, "tierra desocupada", y, por lo tanto, susceptible de apropiación sin consideración de los aborígenes que lo habitaban desde tiempos inmemoriales. Bush eventualmente se convirtió en un sonido ubicuo, arquetípicamente australiano, que evoca nociones idealizadas sobre el sentido de pertenencia y del ser australianos.
} 
más destructiva y costosa en la historia de Australia. ${ }^{2}$ El argumento rector es que los incendios a discusión fueron el producto de condiciones climáticas y antropogénicas complejas y entrelazadas. Esto significa que los incendios no se pueden definir como desastres naturales sin más. En cambio, hubo factores humanos concretos que exacerbaron, y continuarán exacerbando, la severidad y los daños de desastres como el que aquí se expone. ${ }^{3}$ Uno de los propósitos de este ensayo es poner de relieve los efectos que han tenido varias décadas de políticas ambientales débiles, discontinuas y mal informadas por parte de sucesivos gobiernos federales australianos. Estos antecedentes políticos han dado lugar a la ausencia de una estrategia federal robusta y coordinada de prevención y atención a los incendios, con la consecuente pérdida de vidas, infraestructura y daño ambiental que generaron los fuegos catastróficos de 2019 y 2020.

La coyuntura política no ha sido, sin embargo, el único factor humano que agrava los daños a vida, propiedad y medio ambiente de las estaciones de incendios en Australia. De igual o mayor importancia ha sido el crecimiento demográfico descontrolado. Este crecimiento ha sido resultado de una estrategia de desarrollo inmobiliario que desde hace más de medio siglo se ha basado en la expansión de zonas residenciales de alto valor hacia ecosistemas críticos para el mantenimiento adecuado de regímenes climáticos a lo largo de todo el continente. Como se verá, parte clave de la continuidad de esos ecosistemas es precisamente la presencia estacional de incendios forestales — que resultan cada vez más destructivos en vista del crecimiento residencial exurbano.

Finalmente, otro factor preponderante en la severidad registrada de los incendios en Australia y otras partes comparables del mundo es el calentamiento global. En este artículo se explica la manera en que el cambio climático está potenciando condiciones extremas en los fenómenos climáticos que regulan las condiciones medioambientales macrorregionales de toda la zona del Indo-Pacífico, desde África hasta Australia. El consenso científico es que

\footnotetext{
${ }^{2}$ Ha habido cuando menos dos estaciones de incendios, en 1955 y 1974-1975, en las que fue afectada una cantidad mucho mayor de millones de hectáreas. Del mismo modo, ha habido estaciones mucho más trágicas en términos de destrucción de vidas humanas e infraestructura. La de 2019-2020 podría considerarse la tercera más grande, en términos de millones de hectáreas de superficie afectada. Pero un punto importante de diferencia entre los incendios recientes y los del siglo XX es que la frecuencia y la intensidad de cada estación de incendios han ido en aumento a lo largo de las últimas dos décadas.

3 "Cuando no se ha planificado ni se han realizado preparativos adecuados, los peligros de la naturaleza en un momento dado dan lugar a daño y pérdidas de vida, de sustento y de infraestructura —en efecto, dan lugar a un desastre" (Kelman 2020, 18-19).
} 
estos extremos climáticos van en aumento y seguirán incidiendo en la generación de desastres de agua y fuego futuros sobre el territorio australiano y las naciones vecinas del Sureste de Asia y el Pacífico occidental. Las limitaciones que presenta la política ambiental de Australia se ven, en este sentido, magnificadas por una postura internacional poco comprometida con metas ambiciosas para enfrentar el peligro que supone la crisis climática planetaria.

En este contexto, resulta importante dar cuenta de la larga historia de coevolución y gestión medioambiental de los aborígenes australianos, sobre todo en relación con la gestión estacional del fuego y de los incendios. La naturaleza árida pero sustentable del mosaico biocultural australiano es producto de muchos milenios de gestión antropogénica de la flora, la fauna, el agua y el fuego. Es desde la perspectiva de la historia y la antropología ambiental como se están empezando a recuperar algunas de estas prácticas y conocimientos, tanto en el terreno, por ejemplo mediante la incorporación de expertos aborígenes a brigadas de gestión de incendios, como en el diseño de políticas y perspectivas públicas ambientales más sensibles a la vocación de los suelos, el agua y la preciosa biodiversidad endémica del continente austral — de los cuales depende, en última instancia, la viabilidad presente y futura de esa nación.

"Hemos visto una tendencia desde 2009 de estaciones secas más largas y lluvias menos frecuentes, estamos viendo que entra menos humedad a los suelos, lo cual interrumpe el crecimiento arbóreo, y termina estresando a los árboles.”

Tony Johnstone, citado en Whitey (2019)

\section{ANTECEDENTES CLIMÁticos}

Desde tiempos inmemoriales Australia ha poseído una geografía caracterizada por climas áridos y limítrofes para la vida humana. Desde la llegada de las primeras sociedades humanas al continente austral, hace más de 60 milenios, la gestión del agua y del fuego se convirtieron en procedimientos elementales para garantizar la viabilidad de innumerables ecosistemas y de la biodiversidad que encierran. El pasado del clima y la geografía australiana estuvo marcado profundamente por la extraordinaria capacidad adaptativa de centenares de 
comunidades sociolingüísticas aborígenes que transformaron e hicieron sustentables los magros recursos ambientales que conformaban su territorio ancestral.

En el contexto actual de prosperidad económica, crecimiento y consumo acelerados y calentamiento global, las intervenciones humanas sobre los ciclos climáticos básicos de agua y fuego en Australia se han vuelto aún más esenciales para resguardar la seguridad alimentaria y la viabilidad de las sociedades humanas que habitan sobre aquella geografía (Driscoll et al. 2010). Es por eso preocupante la deriva política que caracteriza la política y las relaciones socioambientales de la Australia contemporánea.

Durante los dos años que transcurrieron entre junio de 2017 y junio de 2019, Australia experimentó las temperaturas promedio más altas desde que comenzaron los registros nacionales en 1961 (Bureau of Meteorology 2019). Durante ese periodo de 24 meses se documentaron, además, los extremos de temperatura alta y baja más intensos en el registro histórico del continente austral (Bureau of Meteorology y CSIRO 2020). En perspectiva macrorregional estos extremos se derivaron de patrones atípicos de actividad en relación con tres diferentes fenómenos atmosféricos complejos e interrelacionados.

El primero de estos fenómenos es la oscilación climática predominante del océano Índico conocida como el Dipolo del océano Índico, un patrón de vientos tropicales que regulan el monzón en el subcontinente asiático y generan temperaturas de superficie oceánica que oscilan de calientes a frías en distintos extremos del Índico (Wang y Cai 2013). El segundo de los fenómenos macroclimáticos que informan las variaciones estacionales en Australia es conocido como el Modo Anular del Sur, u oscilación antártica, que consiste en un cinturón de vientos fuertes de baja presión que circulan la tierra de poniente a oriente sobre una banda ubicada en latitudes circunpolares. El tercer fenómeno climático regional son los vientos alisios predominantes del Pacífico Sur que soplan de poniente a oriente y suelen llegar a la costa este y noreste de Australia en una banda de humedad ubicada sobre latitudes subtropicales (Marshall et al. 2014).

Entre 2017 y 2019 la masa de aire del Modo Anular del Sur sufrió un desplazamiento atípico y dilatado hacia el sur, hacia la Antártida. Esto dejó descubierto el espacio atmosférico de las latitudes subtropicales sobre la costa sudoriental australiana, por la cual los vientos alisios del Pacífico Sur pudieron forzar una masa mayor de aire húmedo hacia el centro árido 
de Australia. Ahí, el aire frío del Pacífico chocó con las masas de aire caliente del desierto central, dando lugar a contraflujos de presión atmosférica que expulsaron vientos secos del interior del continente hacia sus zonas húmedas costeñas. Al no haber permanecido estable sobre las zonas costeñas y de montaña, la humedad que transportaban los vientos alisios del Pacífico Sur se perdió en el interior desértico del continente y dio lugar a menores volúmenes promedio de precipitación sobre las costas orientales y sudorientales de Australia. En suma, el desplazamiento atípico del Modo Anular Sur puso en marcha una serie de procesos climáticos complejos que resultaron en el desplazamiento de masas de aire seco desde el interior desértico australiano hacia aquellas regiones de vegetación semiárida y húmeda propias de los montes y valles cercanos a las costas oriental y sudoriental. El resultado eventual fue un aumento notable de condiciones de sequía y riesgo de fuego en casi todo el bushland del oriente y sur del continente austral (Fogt y Marshall 2020).

En ese mismo periodo el Dipolo del océano Índico permaneció en un estado extremo de temperaturas oceánicas altas en su zona occidental, las cuales generaron lluvias torrenciales sobre las costas orientales de África. Mientras tanto, del otro lado del océano Índico, el extremo opuesto del Dipolo mantuvo temperaturas oceánicas frías, lo cual produjo condiciones de muy baja precipitación sobre Indonesia y la región septentrional de Australia.

La manera en que estos tres fenómenos se superpusieron, oscilando entre estados extremos de sequedad y humedad, en combinación con masas de vientos circunpolares escasos y poderosos, es sumamente complicada de modelar y representar, y no está dentro de los objetivos ni límites de este texto ofrecer una discusión pormenorizada al respecto. Lo que aquí importa es dar cuenta del consenso científico en torno al hecho de que la incidencia coyuntural de los tres fenómenos en estados limítrofes prolongados — limítrofes en contraste con el promedio de su actividad y estatus interanuales previamente registrados - se atribuyen al calentamiento atmosférico reciente de nuestro planeta, potenciado por el cambio climático antropogénico (p. ej. Wang y Cai 2013; Cai et al. 2014; Fogt y Marshall 2020).

El resultado de estas alteraciones atmosféricas fue una onda calurosa sostenida que derivó en lluvias escasas y sequía severa en las regiones sur y sureste del territorio australiano durante el periodo 2017 a 2019. La sequía extrema se combinó con vientos poderosos y secos del interior del continente, dando lugar a condiciones óptimas para la propagación de 
incendios forestales. Fueron estas condiciones las que adelantaron por casi ocho semanas, con relación al promedio anual, el inicio de la estación de incendios que se registró en 2019 sobre el territorio norte australiano.

Así lo registró Tony Johnstone, director interino del Servicio de Incendios y Emergencias de Queensland, quien declaró en junio de 2019 que “en Queensland la estación de incendios normalmente comienza en agosto - pero ya hemos visto fuegos erráticos este mes en los entornos de Warwick y Santhorpe, en el Cinturón de Granito, así como en las cercanías de Longreach, alrededor de la zona centro-occidente del estado" (citado en Whitey 2019). A su vez, el reporte mensual de peligros naturales correspondiente a junio de 2019 , emitido por el grupo de Estudio para Incendios y Peligros Naturales (Bushfire and Natural Hazards Study Group) del Centro del Gobierno Australiano para la Investigación Cooperativa (Australian Government Cooperative Research Centre, CRC, por sus siglas en inglés), advertía que “El Territorio del Norte está experimentando su estación de lluvias más seca desde 1992. Combinado con la estación de lluvias más calurosa en nuestros registros, esto resultó en una disminución de 34\% en la caída promedio de largo plazo de las lluvias en esa región” (CRC 2019).

La sequedad multianual que estaban exhibiendo los suelos y bosques en el noreste, sur y sureste de Australia se imbricó con el estado disminuido de capacidades en que durante más de dos décadas habían permanecido diversos servicios de emergencia y gestión medioambiental con relación al estudio y atención de incendios (Climate Council 2019a). La politización de la estrategia ambiental federal afectó de manera múltiple, lateral y acumulativa la capacidad de aquellos sectores del gobierno y la sociedad civil dedicados a gestionar los desastres de fuego. Los efectos de esta política ambiental han comprendido desde recortes sistemáticos para el financiamiento de la ciencia climática en organismos gubernamentales hasta la falta de renovación y ampliación de numerosos equipos de bombero en diferentes estados australianos, lo cual resultó en una capacidad disminuida de respuesta durante la estación de incendios de 2019-2020.

Pero las condiciones de destrucción de propiedad y vidas humanas en ese periodo no se debieron únicamente a factores de coyuntura de insuficiencia de política ambiental y extremos atmosféricos. También fueron potenciadas por procesos históricos modernos que 
han derivado en una intrusión cada vez mayor de asentamientos humanos sobre territorios boscosos que dependen precisamente de los incendios estacionales para su adecuada continuidad. Vale la pena detenerse un momento en estos procesos, en vista de su importancia para el contexto australiano, pero también de otras partes del mundo - costa oeste de Estados Unidos, costas del noratlántico europeo, en particular Galicia, Portugal y Bretaña, y algunas otras regiones de Sudamérica, África, Asia y Medio Oriente.

"Estamos aterrados del fuego. Pero no siempre fue así." Bruce Pascoe $(2018,161)$

\section{RELACIONES SOCIOAMBIENTALES PASADAS Y PRESENTES}

Más allá de coyunturas políticas y del calentamiento global, ha habido en Australia, como en otros países comparables como Estados Unidos, una incapacidad histórica para lidiar con paisajes arbóreos y suelos de vocación semiárida que dependen de regímenes cíclicos de fuego para su adecuada reproducción y sustentabilidad. Este ensayo no permite ofrecer un comentario extenso al respecto, pero baste con señalar que la flora australiana está habituada, como consecuencia de casi 70000 años de coevolución humano-ambiental, a regímenes simbióticos de interacción con poblaciones humanas que generan y gestionan los incendios controlados necesarios para la reproducción adecuada de esos ecosistemas áridos (Flannery 1998; Pyne 1991).

En Australia esta relación se desarrolló por las prácticas socioambientales intergeneracionales de los más de 300 grupos lingüísticos a los que se suele etiquetar genéricamente como "aborígenes australianos", una etiqueta propia de los colonos decimonónicos (p. ej., Dawson 1881), que sigue reproduciéndose acríticamente incluso en las escasas publicaciones que se dedican a esta región en el mundo hispanoparlante (p. ej., Cruz García 2007). ${ }^{4}$ A lo largo de 60 milenios el mosaico biocultural de los pueblos

\footnotetext{
${ }^{4}$ Esta manera, aún generalizada, de referirse a los numerosos grupos culturales y lingüísticos de pueblos originarios australianos es una herencia de la tendencia modernista a agrupar a todos estos pueblos bajo un solo rubro primitivista que
} 
originarios australianos dio lugar a una multitud de prácticas de "pastoreo del fuego" (firestick farming) que transformaron al continente árido en una geografía ecológicamente compleja, caracterizada por un mosaico de ecosistemas interdependientes, capaces de sostener a una población total sustancial, culturalmente diversa, de más de 300 comunidades sociolingüísticas humanas. ${ }^{5}$

Originalmente se teorizaba que las prácticas de gestión del fuego se centraban en la generación de numerosas especies de árboles y arbustos que se volvieron genéticamente codependendientes de los incendios gestionados por los humanos para su reproducción y rebrote idóneos. El dato fundamental de esta explicación era y sigue siendo certero, a saber, que los ciclos antropogénicos de fuego y regeneración regulaban los ciclos de vida de ciertos animales que se congregaban en torno a los brotes de vegetación semiárida generados por la gestión humana del fuego. El desplazamiento estacional de esta fauna se veía reflejado por un correspondiente desplazamiento de grupos humanos trashumantes, cuya forma de vida reflejaba el modelo clásico de cazador-recolector preagrícola.

Los estudios pormenorizados de tipo arqueológico, paleoantropológico, genético y ecológico de la gestión de fuego de los grupos aborígenes australianos son recientes: únicamente comenzaron a tomar forma hacia finales de la década de 1960, con el reconocimiento por el historiador ecológico Rhys Jones de que los aborígenes australianos eran algo más que salvajes de la Era de Piedra, incluso poseedores de prácticas socioambientales sofisticadas y sumamente efectivas (Jones 1969). ${ }^{6}$ Este reconocimiento abrió las puertas para la generación de investigaciones cada vez más complejas acerca del Pleistoceno Tardío en Australia, las cuales han ido dando cuenta pormenorizada de cómo, desde 60000 años antes del presente (Clarkson et al. 2017), generaciones incontables de

erosiona su complejidad sociocultural, geográfica e histórica en aras de representarlos como sociedades de "cazadoresrecolectores trashumantes" atrapadas en una Edad de Piedra indistinta. Es indispensable por esto insistir en que el término "aborígenes australianos" nos refiere a un continente heterogéneo de cientos de sociedades, con lenguas, historias, territorios y sistemas de valor y conocimientos distintivos. El etnónimo reciente, con el que se autodenominan los cientos de pueblos aborígenes y con el cual pretenden resaltar su heterogeneidad cultural pasada y presente, es simplemente el de indígenas australianos (indigenous australians).

${ }^{5}$ Los estudios clásicos al respecto incluyen los de Jones (1969), Gould (1971), Russell-Smith et al. (1997) y Bliege (2002), entre otros.

${ }^{6}$ Rhys Jones también realizó estudios sobre la gestión medioambiental de los bosques de Nueva Inglaterra al contacto con europeos y fue colega influyente de Inga Clendinnen, quien escribió con enorme lucidez sobre la historia socioambiental de Yucatán en el siglo XVI (Clendinnen 1987). 
aborígenes perfeccionaron la gestión y transformación de sus paisajes regionales mediante el uso especializado del fuego. ${ }^{7}$

En consecuencia, la idea de que las sociedades australianas eran fundamentalmente trashumantes refleja el estado del conocimiento que hasta hace pocos años se seguía teniendo de la prehistoria de este territorio. Sin embargo, en la última década han surgido nuevos estudios que comienzan a revolucionar nuestra idea acerca de la naturaleza de la organización social y productiva de los primeros pueblos australianos. En estudios pioneros como los de Rupert Gerritsen, Bill Gammage y Bruce Pascoe se sintetiza una cantidad considerable de datos previamente dispersos o de reciente descubrimiento que sugieren que las sociedades indígenas de la Australia prehistórica eran trashumantes, pero también agrícolas, toda vez que su gestión de la fauna y la flora australianas no estaba limitada a ciclos estacionales de germinación y desplazamiento. El estado de la cuestión actual recupera de manera persuasiva la heterogeneidad cultural, lingüística y territorial de los más de 400 grupos lingüísticos preeuropeos, para arrojar una reconstrucción de la historia ambiental australiana plena de ecosistemas socioambientales sutiles, fértiles, resilientes y sostenibles... pero sobre todo de naturaleza semiagrícola y semitrashumante (Gerritsen 2008; Bradstock et al. 2012; Gammage 2011; Pascoe 2018).

Las consecuencias de esta revolución en nuestro entendimiento de la dilatada prehistoria australiana son considerables, toda vez que constituyen un reto más al viejo modelo evolucionista que planteaba etapas de progreso y complejidad social que comenzaban con comunidades pequeñas de grupos y tribus trashumantes que eventualmente alcanzaban etapas más sofisticadas de organización social propias de los pueblos sedentarios y las primeras sociedades urbanas. El estudio de la gestión del fuego de los indígenas australianos ofrece una de las ventanas más importantes para repensar y replantear modelos sociales sumamente longevos, los cuales no daban cuenta de los complejos procesos de coevolución e historia ambiental que vinculan a personas, fauna y flora a geografías particulares, con regímenes y ciclos climáticos locales y regionales.

\footnotetext{
${ }^{7}$ Algunos de los estudios más destacados en relación con la larga historia ambiental de los pueblos aborígenes de Australia incluyen a Gould (1971), Pyne (1991), Flannery (1998), Bowman et al. (2004), Bliege et al. (2008), Bradstock et al. (2012), Gammage (2011) y Pascoe (2018).
} 
En esta revisión de viejas certidumbres acerca de la prehistoria remota residen datos y nuevos paradigmas socioambientales insoslayables para repensar la relación de la sociedad australiana contemporánea con su clima y su geografía.

Uno de los procesos históricos más importantes de la milenaria simbiosis humanoambiental del territorio australiano prehistórico fue su desarticulación acelerada como consecuencia de la invasión europea del continente a finales del siglo XVIII (p. ej., Boyce 2013). La subsecuente transformación radical de los suelos y paisajes previos hacia vocaciones ganaderas, agroindustriales y más recientemente residenciales ha dado lugar a la casi total destrucción de la capacidad previa de gestión humana del fuego de la que depende la sustentabilidad de los ecosistemas áridos del continente insular:

La fertilidad motivada por la crianza cuidadosa de los suelos se destruyó en unas cuantas estaciones. Los pastizales frondosos de ñame de la zona de Victoria desaparecieron en cuanto las ovejas los comenzaron a consumir, dado que los dientes de los animales llegaban hasta el nivel del suelo, destruyendo las hojas y raíces mismas del pasto.

La población pastoril inglesa no tenía manera de entender que la fertilidad que tanto halagaron durante su primera llegada al nuevo territorio era el resultado de una sutil gestión humana, y la miopía cultural subsecuente aseguró que la transformación de la naturaleza del territorio jamás fuera atribuida a sus propias formas de agricultura introducidas (Pascoe 2018, $11)^{8}$

Desde mediados del siglo XX el crecimiento de ciudades, suburbios y exurbios se convirtió en el elemento determinante de la historia actual del fuego en relación con las costas y el hinterland australianos.

Al igual que en el contexto estadunidense, el crecimiento exurbano en Australia se desprende de políticas de expansión demográfica y residencial hacia zonas de alto riesgo de incendios, pero que resultan atractivas por estar inmersas en zonas de cubierta arbórea distantes de núcleos metropolitanos. El atractivo percibido de vivir en contextos de alta belleza natural no es casual ni evidente, representa uno de los objetivos más importantes de la narrativa de la mercadotecnia inmobiliaria que desde mediados del siglo pasado ha potenciado la expansión periurbana de alta renta hacia zonas de belleza natural. En relación

\footnotetext{
${ }^{8}$ Véanse también Rolls (1981) y Griffiths (2002).
} 
con el problema de los desastres de fuego, resulta significativo que esta narrativa se sustente en la convicción de que las áreas semirrurales, boscosas y semiáridas exurbanas pueden ser gestionadas a la manera de enormes parques o reservas ambientales para el disfrute de sus nuevos habitantes (Pyne 1991).

En otras palabras, la expansión residencial hacia zonas de alto riesgo de incendio en Australia y otros lugares, como California o Galicia, se ha visto acompañada por estrategias de domesticación de paisajes silvestres. Esta estrategia se sustenta en la supresión de los incendios en tanto resultan peligrosos para la vida humana, al mismo tiempo en que se extiende la huella residencial humana sobre esas mismas zonas. Esto equivale a una fórmula esquizoide de conservación que se basa en la supresión de incendios en geografías históricamente dependientes de los incendios para su reproducción idónea.

Los efectos predecibles de este fenómeno han sido décadas de incendios que irrumpen cada vez con mayor ferocidad sobre áreas residenciales, en vista de que éstos son cada vez más extensos, densos y numerosos. La consecuente destrucción de vidas y propiedad humanas se observa con claridad en el incremento anual de desastres de fuego que están sufriendo Australia y otras partes comparables del hemisferio norte. Nada de la manera en que se desenvuelven estos procesos resulta estable ni sustentable ni mucho menos natural. Pero se ha vuelto parte del mosaico socioambiental que caracteriza las regiones de mayor densidad poblacional en Australia (Pyne 1991).

Así las cosas, hacia el final del otoño austral de 2019 las condiciones estaban sentadas para una estación de incendios sin precedentes. 
"Es sumamente decepcionante que no se nos hiciera caso antes, puesto que habíamos predicho exactamente lo que está ocurriendo ahora." Greg Mullins, anterior jefe de Incendios y Rescate de Nueva Gales del Sur, 14 de noviembre de 2019 (ABC News 2019). ${ }^{9}$

\section{OTOÑO DE 2019}

En abril de 2019 se conformó en Australia una agrupación denominada Líderes de Emergencias para la Acción Climática (ELCA, por sus siglas en inglés: Emergency Leaders for Climate Action). ELCA fue creada de manera urgente por 23 ex jefes de bomberos y servidores públicos especialistas en el combate de incendios, quienes habían advertido la conjunción de anomalías climáticas que anticipaban una estación de incendios sin precedentes (ELCA 2019; véase también Climate Council 2019b).

En concreto, las principales preocupaciones presentadas por ELCA en su primer comunicado público fueron

- Que las estaciones de incendios se han estado extendiendo año con año, junto con los días promedio de temperaturas extremas.

- Que la implementación de incendios controlados se complicaba debido a que los inviernos secos y calurosos incrementan el volumen de materia combustible y se traducen en siniestros más difíciles de controlar.

- Que bajo condiciones previas las estaciones de incendios en Australia y en el hemisferio norte, principalmente Canadá y Estados Unidos, solían ocurrir de manera seriada, es decir, una después de la otra, lo cual permitía el traslado internacional de personal y equipo especializado para el combate al fuego - especialmente de aviones cisterna, de los cuales Australia carece debido a una política federal deliberada de discontinuar su financiamiento, pero también de camiones y bomberos voluntarios necesarios para el combate de incendios de dimensiones mayores.

\footnotetext{
9 "It is very, very disappointing that we weren't listened to earlier because we actually predicted exactly what's happening now."
} 
- Que la política climática federal de los últimos cuatro años [2015-2019] había resultado en un incremento en la emisión de gases de efecto invernadero al mismo tiempo en que había supervisado el recorte generalizado de financiamiento para servicios de emergencia y de salud a nivel local, comunitario, a lo largo de toda Australia (ELCA 2019).

En este contexto hacían un llamado al primer ministro, Scott Morrison (Partido Liberal de Australia), a que accediera a reunirse con un grupo de ex líderes de servicios de emergencia que pudieran delinear, libres de prejuicio político y contractual, las amenazas que suponía el cambio climático. En el mismo comunicado pedían a Morrison que reconociera la necesidad de abandonar la estrategia liberal de trasladar a los gobiernos estatales y territoriales la responsabilidad y el coste del mantenimiento de servicios y equipo especializados para el combate al fuego. Finalmente, invitaban al primer ministro a invertir en investigación científica aplicada dirigida a la mitigación y resiliencia contra incendios y otros desastres naturales, en vista del riesgo incrementado que para los mismos supone el cambio climático (ELCA 2019).

Desde ese momento, y durante todo el resto de 2019, los expertos de ELCA buscaron reunirse con Scott Morrison y con personal del Departamento de Asuntos del Interior (Department of Home Affairs), del cual depende la oficina de Gestión de Emergencias (Emergency Management Australia), encargada de coordinar la respuesta nacional a incendios forestales. En vista de que las advertencias de ELCA ponían de relieve el vínculo entre el riesgo de incendios elevados y el cambio climático, así como las fallas percibidas en la política climática del gobierno federal, Morrison se dedicó sistemáticamente a evadir sus llamados.

Las evasiones de Morrison se han convertido en una de las anécdotas más comúnmente citadas para poner de relieve el fracaso de la respuesta del gobierno federal australiano en relación con la estación de incendios de 2019-2020 (p. ej., ABC News 2019; Offer 2019; Keneally 2020). En el último subapartado de este artículo se abordan los problemas que arrastraba la política ambiental federal desde inicios del presente siglo, los cuales explican en parte la reacción de Morrison y su partido político en relación con las 
preocupaciones de ELCA y otros grupos comparables, como el Climate Council. ${ }^{10}$ Antes, sin embargo, se desglosan las preocupaciones de ELCA en el contexto inmediato previo a los incendios de 2019. De este modo se puede comprender mejor el entresijo de procesos coyunturales y estructurales que han dado lugar a la "nueva normalidad" que supuso el parteaguas de 2019 para el estado presente y futuro del clima austral.

Como indicaba ELCA en su comunicado, el inicio de la estación de incendios de 2019 se había adelantado por casi dos meses a la media anual previa. Uno de los principales factores climáticos que incidieron en ese adelanto había sido la sequía prolongada que sufrió el continente australiano desde inicios de 2017. En los dos años posteriores, hasta el otoño de 2019, la sequedad extrema había devastado gran parte de la productividad agrícola de la cuenca Murray-Darling, que comprende los terrenos agropecuarios más extensos, así como seis de los siete ríos más grandes de Australia. La sequía de 2017-2019, a su vez, se relacionaba con una escasez creciente en la frecuencia multianual de lluvias estacionales desde mediados de la década de 1990. Por su parte, la tendencia de mayor escasez de precipitación venía acompañada por una curva ascendente de temperaturas altas extremas multianuales. ${ }^{11}$ En su conjunto, estas tendencias de mediano y largo plazo se tradujeron en una intensificación de la aridez general que presenta la mayoría de las ecorregiones australianas.

Esa aridez generalizada explica la preocupación de ELCA por el aumento notable en el grado de combustibilidad que registraban numerosos ecosistemas de pastizal y cubierta arbórea el otoño de 2019. La combustibilidad aumentada era resultado del incremento en el volumen de materia orgánica seca, principalmente detritus vegetativo, que se acumulaba a nivel del suelo y no había sido adecuadamente eliminado en años previos a través de incendios controlados. En otras palabras, al margen de las condiciones medioambientales largas e inmediatas, existieron antecedentes de política climática que empeoraron el horizonte de riesgo de los incendios descomunales de ese año. En concreto, los incendios

\footnotetext{
${ }^{10}$ El Consejo Climático, o Climate Council, fue fundado en 2013 por un grupo influyente de expertos ambientales y actores prominentes en la política y la vida cívica australiana que hicieron suya la misión de amplificar y hacer más eficiente la presentación pública de información confiable acerca de la emergencia climática, en vista de la ofuscación y negacionismo de sucesivos gabinetes federales.

${ }^{11} \mathrm{La}$ tendencia de altas temperaturas sin precedentes fue confirmada nuevamente por el propio Buró Meteorológico tiempo después, cuando presentó su informe anual reportando que "2019 fue el año más caliente en el registro histórico" (Bureau of Meteorology 2020).
} 
controlados no habían podido ser adecuadamente gestionados en años previos como consecuencia del programa de recortes generalizados que sucesivos gobiernos liberales habían aplicado a los servicios de emergencia locales y comunitarios, bajo el principio de que el coste y la responsabilidad de la gestión de desastres naturales corresponde a los gobiernos estatales y territoriales. ${ }^{12}$ En efecto, el plan nacional estratégico para el combate a los desastres ambientales vigente en otoño de 2019 ponía de relieve que "las respuestas más efectivas para el cambio climático son específicas del contexto en que ocurren, y por lo tanto son mejor atendidas a nivel local y regional" (Commonwealth of Australia 2015, 5).

En suma, en el otoño de 2019 se conjuntaron una sequía extrema con extremos de temperatura cálida, así como con una tendencia en descenso de la precipitación multianual y con una extensión en la intensidad, duración y escala de las estaciones de incendio. Además, estas condiciones de coyuntura estaban siendo potenciadas por los efectos combinados de las tres anomalías climáticas macrorregionales que se explicaron en el primer apartado de este artículo. En conjunción, estos extremos climáticos de corta y larga duración sugerían que Australia enfrentaba un contexto de riesgo sin precedentes directamente relacionado con los efectos múltiples e imbricados del cambio climático. ${ }^{13}$

Como ya se indicó, fue la sugerencia de que el cambio climático representaba el trasfondo causal de las condiciones aumentadas de riesgo lo que chocó con la narrativa política y mediática del gobierno de Morrison. Como se explica en la sección final de este texto, desde 1997 tanto la prensa conservadora como sucesivos gabinetes liberales se han dedicado sistemáticamente a negar y minimizar el calentamiento global y el cambio climático en aras de defender el statu quo de una política energética sustentada en la extracción y utilización de combustibles fósiles (cf. McKnight 2010; Christoff 2013; Taylor 2014). Los resultados de esta campaña de negacionismo climático son numerosos: han incluido una disminución sistemática en el financiamiento para la ciencia climática, una filosofía de

\footnotetext{
${ }^{12}$ El documento clave en que se presentó por vez primera esta estrategia fue producido por el Consejo Selecto para el Cambio Climático (Select Council on Climate Change), un cuerpo conformado ad hoc para bosquejar los principios de la estrategia climática federal que entró en vigor en 2015. Véanse Select Council on Climate Change (2012) y Commonwealth of Australia (2015).

${ }^{13}$ Una de las fuentes clave que sugerían una relación directa entre las condiciones climáticas de 2019 y el cambio climático fueron los reportes mensuales y anuales del propio Buró de Meteorología. Los datos desglosados para esas tendencias se pueden consultar en el Climate Council Briefing Paper 2019. A posteriori, diversos estudios independientes han confirmado la advertencia de que estos extremos climáticos sobrelapados fueron resultado de los efectos del calentamiento global sobre los ecosistemas australianos (Abram 2019; Thompson 2020).
} 
adhesión al libre mercado en tanto contexto regulador de la transición energética a manos de la iniciativa privada - en sustitución de un papel rector más claro para las autoridades nacionales - , y el desplazamiento de la responsabilidad de hacerse cargo de la respuesta a desastres nacionales del gobierno federal a los gobiernos estatales y territoriales.

Para ELCA, la preparación y respuesta a los desastres naturales en un contexto de riesgo catastrófico generalizado exigía una movilización extraordinaria de recursos y de coordinación transversal e interinstitucional que únicamente podría lograr el gobierno federal. Era en atención a esas preocupaciones y medidas extraordinarias de preparación y respuesta que desde abril de 2019 los expertos de aquella agrupación buscaron concertar una reunión urgente con el gobierno de Morrison. Al cabo de 2019 sus más de 20 solicitudes fueron ignoradas.

Poco después comenzaron los incendios.

"El fuego no solamente fue más extenso, intenso, y perdurable; se hizo impredecible. Australia ardió desde el final del invierno hasta el final del verano, desde Queensland hasta Australia Occidental, desde la Isla del Canguro hasta Tasmania, desde las Colinas de Adelaide

hasta Gippsland Oriental, y en los Grandes Bosques Occidentales, así como a lo largo y ancho de la costa oriental [...] Los incendios representaron un momento liminal para la nación, aterrizándonos sobre la playa de un temible futuro planetario.”

Tom Griffiths $(2021,21-23)$

LOS INCENDIOS DE 2019-2020

Los primeros incendios severos comenzaron a aparecer en la zona septentrional de Queensland y los Territorios del Norte en junio de 2019. Éstos son los estados en donde comienza el ciclo anual de incendios forestales en Australia, el cual coincide con el inicio de la primavera austral. Pero en pleno invierno de 2019 la temporada de fuegos estaba iniciando con dos meses de anticipación. Más aún, se estaba caracterizando por fuegos erráticos y 
condiciones particularmente adversas para la contención de los mismos: vientos secos, fuertes, condiciones de escasa humedad, y acumulación de combustible orgánico inflamable.

Como ya se indicó, el gobierno de Tony Morrison no atendió los llamados cada vez más urgentes de ELCA y de otros grupos no gubernamentales. En cambio, dejó pasar los meses de julio, agosto, septiembre y octubre restando importancia a la creciente ferocidad que exhibía la ola de incendios que se estaban propagando de norte a sur sobre el interior y las costas orientales del continente. En septiembre el fuego comenzó a impactar diferentes regiones del estado de Nueva Gales del Sur.

En las siguientes semanas los incendios se esparcieron y multiplicaron de forma acelerada. Entre septiembre y noviembre más de 100 incendios importantes se alumbraron y dispersaron sobre la Costa Norte, la Región del Valle de Hunter (a 120 kilómetros al norte de Sydney), las zonas limítrofes metropolitanas del interior occidental del puerto de Sydney, las Montañas Azules, y finalmente la Costa Sur, la zona agrícola sudoriental de Riverina, y hasta la serranía de las Montañas Nevadas. En su totalidad, una proporción enorme del territorio del estado de Nueva Gales del Sur estaba en llamas.

El 12 de noviembre las autoridades de Nueva Gales del Sur, pertenecientes al Partido Laborista, de oposición, declararon una situación de "peligro por incendios catastróficos" vigente para toda la región de Sydney metropolitano conocida como Greater Sydney (New South Wales Rural Fire Service 2019). El 21 de noviembre los primeros incendios empezaron a propagarse sobre la zona costeña del estado de Victoria, más al sur. A mediados de ese mes el primer ministro Morrison viajó secretamente a Hawai‘i con su familia para tomarse una semana de vacaciones. Esa misma semana murieron dos bomberos voluntarios y la ausencia del primer ministro se hizo notar. Morrison fue puesto en evidencia y se vio forzado a interrumpir su descanso en el penúltimo día del mismo, pero el escándalo había estallado. Para finales de diciembre más de 130000 hectáreas de las costas e interior de Victoria estaban siendo consumidas por incendios catastróficos. Decenas de miles de personas, incluidos 3000 turistas, tuvieron que ser evacuadas de docenas de comunidades rurales y costeñas. El 2 de enero de 2020 el premier de Victoria declaró el estado de emergencia.

En noviembre y diciembre se comenzó a propagar una racha catastrófica de incendios en diversas partes del estado de Australia del Sur. Al igual que ocurrió en Nueva Gales, los 
fuegos llegaron a amenazar partes cercanas a la capital del estado, en este caso Adelaide. Pero los incendios más duros se dieron en la costa e islas: especialmente sobre la Península de Yorke y en la Isla del Canguro, en donde el fuego destruyó una parte del Parque Nacional Flinders Chase. Hubo fuegos de gran escala que también se generaron en Australia Occidental, en la isla grande de Tasmania, y en el Territorio de la Capital Nacional, en Canberra. El 23 de enero un avión Hércules C-130 con tres bomberos estadunidenses voluntarios se vino abajo en las cercanías de Cooma, Nueva Gales del Sur, durante maniobras de supresión del fuego.

A inicios de febrero de 2020 hubo un respiro: se dieron lluvias que apagaron casi un tercio de los incendios que aún ardían en todo el país. Esto abrió una ventana de oportunidad para empezar a controlar la catástrofe, aunque aún habrían de transcurrir varias semanas más para que las cosas regresaran a una semblanza de normalidad.

"Estamos enfrentando a un culto climático." Tony Abbott, primer ministro de Australia (2013-2015) ${ }^{14}$

\section{ANTECEDENTES POLÍTICOS: TRES DÉCADAS PERDIDAS}

Los incendios forestales de 2019-2020 no pueden entenderse como un evento natural, atípico ni aislado. Fueron un desastre humano en el sentido estricto del término, es decir, una catástrofe socioambiental exacerbada como resultado de niveles múltiples de acción e inacción humanas. Algunas de esas acciones equivalen a procesos de larga duración, como el crecimiento demográfico descontrolado, mientras que otros reflejan el resultado de una serie acumulativa de decisiones políticas que erosionaron la capacidad de reacción de diversas instituciones y organismos de gobierno. Junto con los incendios catastróficos que devastaron partes de la costa oeste de Estados Unidos durante el verano septentrional de

\footnotetext{
14 Palabras pronunciadas durante una entrevista acerca de los incendios de 2019, grabada el 15 de diciembre de 2019 para el programa de radio israelí The International Hour. La entrevista completa se puede descargar en https://omny.fm/ shows/international-hour/tony-abbott-the-west-is-facing-a-climate-cult
} 
2020, el desastre australiano constituyó una llamada de alerta con relación a las consecuencias de mantener una política ambiental débil y mal informada.

Este subapartado final ofrece un breve esbozo acerca de los principales antecedentes en materia de política ambiental que informaron los límites de la reacción oficial a los incendios de 2019-2020.

La respuesta del gobierno a los incendios de 2019 tuvo como antecedente más de tres décadas de una agenda medioambiental problemática, ambigua, y en ocasiones regresiva, por parte de sucesivos gabinetes federales. Es importante señalar que han sido corresponsables de dicha agenda los dos principales partidos políticos de centro-derecha y centro-izquierda, el Australian Liberal Party (liberales) y el Australian Labor Party (laboristas), respectivamente. Pero es importante señalar también que en el siglo XXI la mayor parte de los gabinetes federales han pertenecido a primeros ministros emergidos del Partido Liberal, cuya postura en relación con el cambio climático ha tendido a ser sumamente complicada, y en muchos sentidos incluso retrógrada (cf. Climate Action Tracker 2020; Climate Council 2020; Climate Targets Panel 2021).

En el caso de Australia son cuatro sectores, o esferas socioambientales, los que concentran los principales retos que confrontan la agenda climática gubernamental. Éstos son: la gestión del agua, la transición energética de combustibles fósiles a energías renovables, el control de emisiones en el marco del calentamiento global, y, el más importante en relación con los incendios, el crecimiento y patrón de dispersión demográfica hacia zonas previamente deshabitadas en los límites externos e internos de áreas diversas de conservación.

En el primer subapartado de este texto se mencionó el reto que supone el crecimiento demográfico desordenado para la política y las relaciones socioambientales en Australia, toda vez que guarda relación directa con los daños a la propiedad y las vidas humanas que generaron los siniestros de 2019-2020. En las siguientes páginas me concentraré en otro de los cuatro grandes retos mencionados al inicio de este texto, a saber, el problema de las emisiones y su importancia para la forma que ha tomado la discusión y el diseño de política climática desde finales del siglo pasado. Sin embargo, conviene recordar que una política 
ambiental eficaz no puede disociar la naturaleza imbricada de los cuatro rubros arriba mencionados.

La mayoría de los estudios independientes y gubernamentales dedicados a diagnosticar la política ambiental australiana desde hace más de una década coinciden en que sucesivos gabinetes federales han sido reacios a afectar los intereses del sector energético dedicado a los combustibles fósiles, notablemente las industrias de gas natural y carbón. Vale la pena mencionar y citar algunos de los estudios más prominentes en orden de aparición cronológica para poder apreciar la consistencia de estudios y opiniones relativas al estado actual de la política climática en Australia.

En 2012, uno de los primeros diagnósticos académicos acerca del estado de la política ambiental australiana en el siglo actual señalaba el arraigo de una "regresión en la política del cambio climático a partir de 1996, la cual ha resultado en una serie de acciones simbólicas acompañadas de declaraciones de 'nada que lamentar' tanto en el ámbito doméstico como en el internacional. Presumiblemente, esto se ha debido a la fuerte influencia política que se desprende de la industria de los combustibles fósiles y los productores del carbón" (Firsova et al. 2012).

Poco después, en 2014, el propio Parlamento Nacional de Australia comisionó un diagnóstico de las principales iniciativas, propuestas y acciones de gobierno en materia ambiental entre 1990 y 2013. En aquel estudio se señala con claridad que la política ambiental nacional ha padecido de una "ambición disminuida por desarrollar una estrategia de mitigación" en aras de no afectar la narrativa económica de crecimiento y boom sustentados en el extractivismo y la continuidad de la industria de combustibles fósiles (Talberg, Hui y Loynes 2016, 1).

Por lo que toca al periodo posterior, de 2014 a 2020 el consorcio internacional de universidades, consultorías y centros de investigación agrupados bajo el rubro del Climate Action Tracker resumió de la siguiente manera los cinco años de política climática correspondientes a los gobiernos liberales de los primeros ministros Malcolm Turnbull (2015-2018) y Tony Morrison (2018-a la fecha): 
El gobierno australiano se ha dedicado a una recuperación económica arraigada en una intensificación del uso de gas natural en lugar de energías renovables, mientras que ha continuado indicando su apoyo a la industria del carbón. El gobierno [del actual primer ministro, Scott Morrison] no ha mostrado ninguna intención de actualizar los objetivos a los que se comprometió en el marco del Acuerdo de París. El primer ministro incluso ha reiterado su desinterés por perseguir objetivos de emisión-cero. En cambio, el gobierno se está enfocando en lo que llama una aproximación de "tecnología neutra", que se contradice por su interés en el desarrollo del gas como energético de preferencia. La inversión en energías renovables ha caído a niveles previos a 2017 debido a la incertidumbre que ha introducido a su política [ambiental] el gobierno de Morrison. El resultado es una carencia de acciones relativas al clima, a pesar del incremento registrado de impactos ambientales tales como los incendios catastróficos que envolvieron a varios estados a finales de 2019 y principios de 2020 (Climate Action Tracker 2020).

En paralelo con esta tendencia regresiva en materia de política medioambiental, desde finales del siglo pasado se fue desarrollando una narrativa pública que contrapone la prosperidad y el crecimiento económicos a las metas de una agenda medioambiental proactiva y progresiva (cf. McKnight 2010; Christoff 2013; Talberg, Hui y Loynes 2016). En coherencia con esta narrativa, en el transcurso de la última década sucesivos gobiernos liberales se han dedicado activamente a limitar y disminuir los recursos financieros e institucionales abocados al estudio del cambio climático. ${ }^{15}$

Dos de los efectos más importantes resultantes de esta complicada agenda y discurso ambientales han sido, 1) la disminución de financiamiento público para el estudio y atención al cambio climático, y 2) una creciente incapacidad institucional para construir plataformas multisectoriales capaces de reunir las preocupaciones y el expertise de actores industriales, científicos y civiles involucrados con temas de energía, clima, producción alimenticia y gestión del agua (al respecto, véanse los análisis de Pittock et al. 2013 y McDonald 2016).

\footnotetext{
${ }^{15}$ El Consejo Climático ha comentado a detalle varios de los problemas que presenta la agenda del Partido Liberal en materia de financiamiento y diseño de política ambiental (Climate Council 2020). La estrategia del Partido Liberal, a su vez, se puede contrastar con la agenda del Partido Laborista, que tampoco resulta particularmente proactiva y progresiva, aunque no cae en el negacionismo climático y el chauvinismo cultural como recursos para justificar la continuidad del statu quo de una economía basada en el extractivismo y los combustibles fósiles (Australian Labor Party Climate Change Action Plan. Fact Sheet 2019).
} 
En vista de la amplia coincidencia que exponen los anteriores diagnósticos acerca de los problemas que presenta la política climática de Australia a lo largo del último cuarto de siglo, resulta útil ofrecer un bosquejo resumido de los principales actores y decisiones gubernamentales que han dado forma a dicha política ambiental. Hacia ese resumen está dedicado el resto de este último subapartado. ${ }^{16}$

En 1997, Australia fue partícipe del Protocolo de Kioto, que en ese momento representaba el foro de negociación internacional más importante, desde la Cumbre de Río en 1992, para enfrentar la emisión desproporcionada de gases de efecto invernadero. En el transcurso de la cumbre el gobierno de John Howard (liberal) mantuvo una actitud poco proactiva en relación con los objetivos básicos del Protocolo de Kioto, buscando ralentizar y diluir cualquier compromiso oficial que pudiera afectar intereses relacionados con los combustibles fósiles. El comportamiento poco colaborativo del equipo negociador australiano en Kioto fue duramente criticado por Estados Unidos, la Unión Europea y las casi 20 naciones independientes de las Islas del Pacífico —que representan los vecinos más próximos de Australia en la región y son particularmente vulnerables a los efectos del calentamiento global. ${ }^{17}$

En el ámbito doméstico la postura del gabinete de Howard generó una fuerte presión pro-ambientalista por una parte importante de la sociedad civil australiana y de los partidos de oposición. En 2006, Howard presentó una propuesta modesta de combate al calentamiento global basada en el comercio de emisiones. En esencia, esta propuesta consistía en la promesa de mantener las emisiones anuales de Australia por debajo de $8 \%$ en relación con las emisiones promedio registradas en 1990. Casi de inmediato numerosos analistas advirtieron sobre el uso tendencioso de cifras en el contraste entre porcentajes reales y declarados de emisiones.

\footnotetext{
${ }^{16}$ La mayor parte de los datos presentados en las siguientes páginas se han extraído de las fuentes citadas a lo largo de este apartado; con el fin de evitar citas reiteradas de las mismas fuentes no en todos los casos se ofrece una atribución pormenorizada de las mismas.

${ }^{17}$ Pese a que presentan minúsculas extensiones territoriales y económicas, conviene recordar que las Islas del Pacífico poseen Zonas Económicas Exclusivas que comprenden enormes extensiones marítimas, con todo lo que eso representa en términos de posicionamiento estratégico de rutas navieras transcontinentales y recursos pesqueros y de fondos minerales oceánicos. Más aún, representan uno de los bloques más grandes y efectivos de presión coordinada en la Asamblea General de las Naciones Unidas.
} 
Concretamente, la promesa de mantener las emisiones australianas por debajo de $8 \%$ en relación con las emisiones registradas en 1990 estaba directamente ligada al débil compromiso ofrecido por el gobierno de Howard previamente, durante la cumbre de Kioto en 1997. Aquella promesa estaba basada en cifras engañosas toda vez que en 1990 hubo un ritmo acelerado, atípico, de deforestación en los bosques australianos, lo cual agregó más de 130 millones de toneladas métricas de bióxido de carbono atmosférico adicionales a las emisiones anuales promedio de años anteriores. Esto significaba que el compromiso de mantener emisiones por debajo de 8\% en relación con la cifra de 1990 le otorgaba a Australia la flexibilidad para aumentar de facto sus emisiones anuales hasta $24 \%$ en comparación con años "promedio" previos.

Los tiempos políticos no favorecieron la puesta en marcha del plan de Howard, el cual terminó integrándose a la plataforma del Partido Liberal con miras a su implementación después de la elección parlamentaria de 2008. La estrecha pérdida electoral que sufrieron los liberales en 2008 se atribuyó, entre otras cosas, a la insatisfacción pública ante la insuficiencia de la política climática del gabinete de Howard.

De mayor trascendencia fue la campaña de desinformación en torno a la existencia misma del cambio climático que fue sembrando el gobierno de Howard desde finales del siglo XX (McKnight 2010). A un cuarto de siglo de su despliegue, ha resultado ser una narrativa engañosa pero efectiva, sobre todo en cuanto a sus rendimientos electorales, y constituye uno de los mayores obstáculos que enfrenta cualquier iniciativa de reforma seria a la modesta plataforma de acciones que ha caracterizado la política ambiental australiana en el siglo XXI. ${ }^{18}$

Durante el periodo 2008 a 2013, el Partido Laborista, con Kevin Rudd y Julia Gillard como primeros ministros, sucesivamente, logró introducir un impuesto a la utilización del carbón que se vio ferozmente criticado por la oposición parlamentaria liberal, así como por intereses corporativos diversos. Para 2011 este impuesto había motivado una reducción de $11 \%$ en la extracción de carbón durante los 24 meses previos. Esta medida se distingue por

\footnotetext{
${ }^{18}$ En la construcción de un imaginario público antiintelectual, anticiencia climática y pro statu quo ha jugado un papel preponderante el gigante mediático australiano de News Corporation, cuya narrativa acerca del cambio climático empezó a manifestar un giro tendencioso desde, cuando menos, 1997 (McKnight 2010; Taylor 2014).
} 
haber sido excepcional dentro del periodo más amplio de iniciativas en materia de emisiones entre 1990 y 2020.

En 2013 el Partido Liberal derrotó a los laboristas en unas nuevas elecciones nacionales. El primer ministro designado entonces fue Tony Abbott, un sujeto que se autodenomina "escéptico climático". Desde el inicio de su gobierno Abbott hizo gala de eliminar el impuesto al carbón iniciado por la administración previa. Este cambio representó una toma de posición radical en el marco de las rondas de negociación previas a la cumbre climática de París que se celebraría en diciembre de 2015.

Las numerosas controversias personales en las que se empantanó Abbott lo llevaron a ser derrotado en un voto interno por el liderazgo del Partido Liberal unos meses antes de la cumbre de París. Su contrincante triunfal, Malcolm Turnbull, asumió la posición de primer ministro en septiembre de 2015. Turnbull se encargó de que Australia hiciera suyas las resoluciones del Acuerdo de París, pero bajo una serie de objetivos diseñados, 1) para no comprometer a Australia a plegarse a la declaratoria internacional deseada de alcanzar “emisiones-cero", y 2) para prolongar sustancialmente el tiempo necesario para alcanzar la reducción modesta de emisiones a la cual se estaba comprometiendo.

Específicamente, los australianos se comprometieron a reducir 30\% las emisiones de gases de efecto invernadero para 2030 — en contraste con otras naciones desarrolladas, cuyos porcentajes eran mucho más ambiciosos, e incluyen el objetivo ulterior de alcanzar “emisiones-cero". A la fecha, a mediados de 2020, la reducción efectiva alcanzada apenas llega a 7\% del total comprometido en 2015. De mantenerse este ritmo Australia tendrá que realizar esfuerzos descomunales para alcanzar siquiera la cifra truncada de $30 \%$ de recortes y cumplir con su objetivo de París en los siguientes 10 años (Chemnik 2020; Climate Targets Panel 2021).

En mayo de 2019 el Consejo Climático presentó un análisis de las distintas plataformas ambientales de los principales partidos políticos australianos, en el que se describen de manera contundente los rezagos que durante más de siete años han arrastrado los tres gobiernos laboristas sucesivos de Abbott, Turnbull y Morrison en materia ambiental: 
El periodo 2013-2019 se caracteriza por recortes radicales al financiamiento de la ciencia climática, recortes para programas eficaces contra el cambio climático, el rechazo de consejos expertos por parte de organismos nacionales e internacionales, declaraciones engañosas de parte de ministros del gobierno, una ausencia de políticas climáticas confiables, y el encubrimiento consistente del pobre desempeño que se ha tenido en este rubro. [...] el Gobierno Federal ha llegado a extremos extraordinarios para tratar de mantener al público en la ignorancia acerca del cambio climático. En consecuencia, Australia no está bien preparada para lidiar con los impactos del cambio climático (Climate Council 2019a, 1). ${ }^{19}$

\begin{abstract}
"Los incendios demostraron que la crisis podía caernos de forma repentina y con tanta fuerza que las premisas básicas de nuestra economía y cultura se verían sujetas a un cuestionamiento radical."
\end{abstract}

Anderson et al. $(2021,13)$

\title{
REFLEXIONES FINALES
}

Los costos totales de la estación de incendios de 2019-2020 en Australia fueron enormes: 34 personas muertas, casi 19 millones de hectáreas afectadas y más de 3500 casas o edificaciones destruidas. Pero la destrucción de fauna, flora y ecosistemas de la nación austral fue mucho mayor. De hecho, es incalculable, en vista de que perecieron ecosistemas enteros. La estimación más confiable al día de hoy, citada al principio de este texto, es la de WWFAustralia, que calcula que hasta 3000 millones de vertebrados terrestres fueron aniquilados o desplazados a ecologías dañadas o inadecuadas. Esta cifra incluye poblaciones de reptiles, pájaros, mamíferos y anfibios endémicos al continente y residentes de un mosaico diverso de ecosistemas frágiles. También incluye varias especies que estaban previamente etiquetadas como "en peligro de extinción” y que se teme hayan perecido para siempre (Flannery 2012).

\footnotetext{
19 "The period 2013-2019 is characterized by slashing climate science funding, cutting effective climate change programs, rejecting the expert advice of national and international bodies, senior ministers publicly making misleading claims, a lack of credible climate policy, and consistently covering up poor performance. [T] he Federal Government has gone to extraordinary lengths to keep the public in the dark on climate change. [...] As a result, Australia is unprepared to cope with the impacts of climate change."
} 
En términos climáticos, los incendios dieron lugar a la emisión de cientos de millones de toneladas de bióxido de carbono a la atmósfera en la forma de cenizas y micropartículas aéreas. Las cifras más precisas hasta ahora han sido las calculadas por la Base de Datos de Emisiones de Fuegos Globales (GFED, por sus siglas en inglés: Global Fire Emissions Database) del Centro de Vuelos Espaciales de Goddard/NASA, en Washington, D. C. En un estudio preliminar el GFED calculó que entre el $1^{\circ}$ de agosto de 2019 y el 2 de enero de 2020 se habían emitido poco más de 300 millones de toneladas de $\mathrm{CO}_{2}$. Esto equivale a la producción, en cinco meses, de dos tercios de las emisiones totales que generó Australia durante todo el año anterior, 2018 (Global Fire Emissions Database 2020).

¿Qué conclusiones se pueden sacar de todo lo hasta aquí relatado? Primero, que la estación de incendios en Australia, como en otras regiones comparables del mundo, es un fenómeno natural que desde hace milenios ha sido parte de los ecosistemas australes. Pero la naturaleza cíclica de esos incendios se ha ido intensificando en el transcurso del presente siglo en respuesta a cuando menos tres factores ligados al calentamiento global antropogénico, a saber, 1) los extremos atípicos atmosféricos que llevan a diferentes patrones de vientos y humedad - tropical, subtropical y circunpolar- a generar condiciones prolongadas y peligrosas de sequedad o humedad, que a su vez potencian las condiciones de lluvias torrenciales y fuegos descomunales sumamente destructivos, 2) la creciente extensión de zonas residenciales humanas hacia geografías frágiles codependientes de regímenes regulares de fuego, y 3) la lamentable politización de la política ambiental por diversos gobiernos y gobernantes, en conjunción con narrativas mediáticas tóxicas propiciadas y en buena medida financiadas por grupos de interés corporativos con inversiones sustanciales en la continuidad de la economía de los combustibles fósiles.

La lección que arroja este panorama es clara: la única manera en que podremos evitar los incendios catastróficos será a partir de políticas ambientales que atiendan la complejidad y peligro que supone para todos los seres vivientes del planeta la emergencia climática que enfrentamos.

Carlos Mondragón es profesor-investigador del Centro de Estudios de Asia y África de El Colegio de México. Su principal línea de investigación es la Antropología Ambiental en 
Asia-Pacífico, con especial énfasis en las islas de Melanesia y la meseta del Tibet, así como la Etnohistoria de Primeros Encuentros en el Pacífico Occidental. Su libro Un entramado de islas (El Colegio de México, 2015) ganó el Premio Nacional de Investigación en Antropología Social del INAH.

cmondragon@,colmex.mx

\section{REFERENCIAS}

ABC News. 2019. "Former fire chiefs 'tried to warn Scott Morrison' to bring in more waterbombers ahead of horror bushfire season." $A B C$ News, noviembre 14, 2019. https://www.abc.net.au/news/2019-11-14/former-fire-chief-calls-out-pm-over-refu $\underline{\text { sal-of-meeting/11705330 }}$

Abram, Nerilie. 2019. "Angry Summer: This Is What Climate Change Looks Like." Scientific American (blog). Diciembre 31, 2019. https://blogs.scientificamerican. com/observations/australias-angry-summer-this-is-what-climate-change-looks-like/

Anderson, Pat, Sally Gardner, Paul James y Paul Komerasoff, eds. 2021. "Introduction.” En Continent Aflame: Responses to an Australian Catastrophe. Melbourne: Palaver, 1316.

Australian Government Cooperative Research Centre: Bushfire and Natural Hazards Study Group. 2019. Northern Australia Seasonal Bushfire Outlook 2019: Hazard Notes, 29 June 2019. https://www.bnhcrc.com.au/hazardnotes/62

Australian Labor Party Climate Change Action Plan. Fact Sheet. 2019. https:// cdn.australianlabor.com.au/documents/Climate_change_action_plan_fact_sheet.pdf

Bliege Bird, R. et al. 2008. "The 'fire stick farming' hypothesis: Aboriginal foraging strategies, biodiversity, and anthropogenic fire mosaics." Proceedings of the National Academy of Sciences 105 (39): 14796-14801.

Boyce, James. 2013. 1835: The Founding of Melbourne \& the Conquest of Australia. Carlton, Victoria: Black Inc. 
Bowman, David, A. Walsh y L. Prior. 2004. "Landscape analysis of Aboriginal fire management in Central Arnhem Land, north Australia.” Journal of Biogeography 31 (2): $207-223$.

Bradstock, Ross, Malcolm Gill y Richard Williams. 2012. Flammable Australia: Fire Regimes and Biodiversity of a Continent. Collingwood, Victoria: CSIRO Publishing.

Bureau of Meteorology. 2019. Annual climate statement 2019. http://www.bom.gov.au/ climate/current/annual/aus/2019/

Bureau of Meteorology y Commonwealth and Industrial Research Organization. 2020. State of the Climate 2020. Canberra: Gobierno de Australia. http://www.bom.gov.au/stateof-the-climate/documents/State-of-the-Climate-2020.pdf

Cai, Wenju et al. 2014. "Increased frequency of extreme Indian Ocean Dipole events due to greenhouse warming." Nature 510: 254-258. https://www.nature.com/articles/ nature 13327

Carbon Brief. 2020. "Media reaction: Australia's bushfires and climate change." Carbon Brief, enero 7, 2020. https://www.carbonbrief.org/media-reaction-australiasbushfires-and-climate-change

Chemnik, Jean. 2020. “As Fires Rage, Australia Pushes to Emit More Carbon.” Scientific American Energy \& Environment News, enero 6, 2020. https://www. $\underline{\text { scientificamerican.com/article/as-fires-rage-australia-pushes-to-emit-more-carbon/ }}$

Christoff, Peter. 2013. "Climate Discourse Complexes, National Climate Regimes and Australian Climate Policy.” Australian Journal of Politics and History 59 (3): 349367.

Clarkson, Chris et al. 2017. "Human occupation of northern Australia by 65,000 years ago." Nature 547: 306-310. https://www.nature.com/articles/nature22968

Clendinnen, Inga. 1987. Ambivalent Conquests. Maya and Spaniard in Yucatán, 1517-1570. Cambridge: Cambridge University Press. 
Climate Action Tracker. 2020. Australia Country Summary. $\underline{\text { https:// }}$ climateactiontracker.org/countries/australia/

Climate Council Briefing Paper 2019. https://www.climatecouncil.org.au/wp-content/ uploads/2019/11/CC-nov-Bushfire-briefing-paper.pdf

Climate Council. 2019a. Climate Policies of Major Australian Political Parties. https:// www.climatecouncil.org.au/wp-content/uploads/2019/05/climate-policies-of-majoraustralian-political-parties-v2.pdf

Climate Council. 2019b. Dangerous Summer: Escalating Bushfire, Heat and Drought Risk. https:/www.climatecouncil.org.au/wp-content/uploads/2019/12/report-dangeroussummer_V5.pdf

Climate Council. 2020. ALP Climate Policy: What You Need to Know. https://www.climatecouncil.org.au/alp-climate-policy-what-you-need-to-know/

Climate Targets Panel. 2021. Australia's Paris Agreement Pathways: Updating the Climate Change Authority's 2014 Emissions Reduction Targets. https://www.climatecollege. unimelb.edu.au/files/site1/docs/\%5Bmi7\%3Ami7uid\%5D/ClimateTargetsPanelRep ort.pdf

Commonwealth of Australia. 2015. National Climate Resilience and Adaptation Strategy. Canberra: Gobierno de Australia. https://www.environment.gov.au/climate-change/ adaptation/strategy

Cruz García, Álvaro. 2007. Aborígenes australianos y del Pacífico. Madrid: Edimat.

Dawson, James. 1881. Australian Aborigines. The Languages and Customs of Several Tribes of Aborigines in the Western District of Victoria, Australia. Melbourne: George Robertson.

Driscoll, Don A. et al. 2010. "Fire management for biodiversity conservation: Key research questions and our capacity to answer them." Biological Conservation 43 (9): 19281939. 
Emergency Leaders for Climate Action (ELCA). 2019. Statement: Australia Unprepared for Worsening Extreme Weather. https://emergencyleadersforclimateaction.org.au/ $\underline{\text { statement/ }}$

Firsova, Anna, Vladimir Stresov y Ros Taplin. 2012. “After 20 years of creating Australian climate policy: was the proposed carbon pollution reduction scheme a change in direction?" Australasian Journal of Environmental Management 19 (1): 21-34.

Flannery, Tim. 1998. The Future Eaters: An Ecological History of the Australasian Lands a and People. Port Melbourne: Reed Books.

Flannery, Tim. 2012. “After the Future: Australia’s new extinction crisis.” Quarterly Essay 48: 1-80. https://www.quarterlyessay.com.au/essay/2012/11/after-the-future

Fogt, Ryan L. y Gareth L. Marshall. 2020. “The Southern Annular Mode: Variability, trends, and climate impacts across the Southern Hemisphere." Wiley Interdisciplinary Reviews: Climate Change 11 (4).

Gammage, Bill. 2011. The Biggest Estate on Earth: How Aborigines Made Australia. Sydney: Allen\&Unwin.

Gerritsen, Rupert. 2008. Australia and the Origins of Agriculture. Oxford: British Archaeological Reports International Series 1874.

Global Fire Emissions Database. 2020. “2019-20 Australian bushfire season.” http:// globalfiredata.org/pages/2020/01/03/2019-20-australian-bushfires/

Gould, Richard A. 1971. "Uses and Effects of Fire among the Western Desert Aborigines of Australia." Mankind 8 (1): 14-24.

Griffiths, Tom. 2002. "How many trees make a forest? Cultural debates about vegetation change in Australia." Australian Journal of Botany 50 (4): 375-389.

Griffiths, Tom. 2021. "It is the season of reckoning." En Continent Aflame: Responses to an Australian Catastrophe, editado por Pat Anderson, Sally Gardner, Paul James y Paul Komesaroff, 19-23. Melbourne: Palaver.

Jones, Rhys. 1969. “Fire-Stick Farming.” Australian Natural History 16 (7): 224-228. 
Kelman, Ilan. 2020. Disaster by Choice: When our actions turn natural hazards into catastrophes. Oxford: Oxford University Press.

Kenneally, Thomas. 2020. "Foreword". En Continent Aflame: Responses to an Australian Catastrophe, editado por Pat Anderson, Sally Gardner, Paul James y Paul Komesaroff, 8-12. Melbourne: Palaver.

Marshall, A. G., D. Hudson, M. C. Wheeler et al. 2014. "Intra-seasonal drivers of extreme heat over Australia in observations and POAMA-2." Climate Dynamics 43: 19151937.

McDonald, Matt. 2016. "Bourdieu, environmental NGOs, and Australian climate politics." Environmental Politics 25 (6): 1058-1078.

McKnight, David. 2010. "A change in the climate? The journalism of opinion at News Corporation." Journalism 11 (6): 693-706.

New South Wales Rural Fire Service. 2019. "Dangerous fire conditions-Tuesday 12 November 2019." Comunicado, noviembre 10, 2019. https:/www.rfs.nsw.gov. au/news-and-media/general-news/dangerous-fire-conditions

Offer, Kaitlyn. 2019. "Ex-emergency chiefs sound climate alarm.” Canberra Times, abril 10, 2019. $\quad$ https://www.canberratimes.com.au/story/6014638/ex-emergency-chiefs$\underline{\text { sound-climate-alarm/?cs=1423 }}$

Pascoe, Bruce. 2018. Dark Emu: Aboriginal Australia and the birth of agriculture. Londres: Scribe Publications.

Pittock, Jamie, Karen Hussey y Samuel McGlennon. 2013. “Australian Climate, Energy and Water Policies: conflicts and synergies.” Australian Geographer 44 (1): 3-22.

Pyne, Stephen J. 1991. Burning Bush: A Fire History of Australia. Nueva York: Henry Holt and Company.

Rolls, Eric. 1981. A Million Wild Acres: 200 Years of Man and an Australian Forest. Melbourne: Thomas Nelson Publishing. 
Russell-Smith, Jeremy et al. 1997. "Aboriginal Resource Utilization and Fire Management Practice in Western Arnhem Land, Monsoonal Northern Australia: Notes for Prehistory, Lessons for the Future." Human Ecology 25 (2): 159-195.

Select Council on Climate Change. 2012. "Roles and Responsibilities for Climate Change Adaptation in Australia". Documento publicado en línea por el Department of Agriculture Water and the Environment. https://www.environment.gov.au/system/ files/pages/2e55e020-e4d3-4e79-bf44-1846f720a8c8/files/coag-rolesrespsonsibilities-climate-change-adaptation.pdf

Talberg, Anita, Simeon Hui y Kate Loynes. 2016. “Australian Climate Policy to 2015: A Chronology." Parliamentary of Australia. https://www.aph.gov.au/About Parliament/Parliamentary_Departments/Parliamentary_Library/pubs/rp/rp1516/Cli $\underline{\text { mate2015 }}$

Taylor, Maria. 2014. Global Warming and Climate Change: what Australia knew and buried... then framed a new reality for the public. Canberra: Australian National University Press.

Thompson, Andrea. 2020. "Yes, Climate Change Did Influence Australia's Unprecedented Bushfires." Scientific American, marzo 4, 2020. https://www.scientificamerican. com/article/yes-climate-change-did-influence-australias-unprecedented-bushfires/

Wang, Guojian y Cai, Wang. 2013. "Climate-change impact on the 20th-century relationship between the Southern Annular Mode and global mean temperature." Scientific Reports 3: 2039.

Watson, Don. 2014. The Bush. Melbourne: Penguin Random House Australia.

Whitey, A. 2019. "Bushfire season starts early across northern Australia due to ongoing hot, dry conditions." ABC News, junio 26, 2019. https://www.abc.net.au/news/2019-0627/bushfire-outlook-queensland-2019/11251150

World Wildlife Fund of Australia. 2020. Australia's 2019-2020 Bushfires: The wildlife toll. Sydney: World Wildlife Fund. https://www.wwf.org.au/what-we-do/bushfirerecovery/in-depth/resources/australia-s-2019-2020-bushfires-the-wildlife-toll 